\title{
DIMENSĀO INTERNACIONAL DOS DIREITOS FUNDAMENTAIS DA PESSOA
}

\author{
José Roberto Franco da Fonseca \\ Professor Associado do Departamento de Direito Internacional \\ da Faculdade de Direito da Universidade de São Paulo
}

\begin{abstract}
Resumo:
Os direitos humanos (que mais corretamente se deveriam denominar "direitos fundamentais da pessoa") têm sido estudados como matéria de direito interno.

Desde a Segunda Grande Guerra, todavia, tem-se entendido que o tema deve ser apreciado sob o foco do Direito Internacional, porque diz respeito ao ser humano, cuja dignidade é a essência deste ramo do Direito.
\end{abstract}

\section{Abstract:}

Human Rights (which should rather be called "essential human rights") have been handled as a subject of internal matter.

Since the Second World War, however, it has been generally accepted that this matter should be dealt under the focus of International Law, because human beings and their values are the heart of the matter.

\section{CONCEITO DE DIREITOS FUNDAMENTAIS DA PESSOA.}

\subsection{Precisões terminológicas.}

A locução "direitos humanos" ou "direitos do homem" (tomada diretamente de empréstimo aos textos clássicos da literatura política do século XVIII) não deve ser adotada, sem maior cuidado de adequação científica, pelo jurista, por conter grave equívoco. É que, no trabalho científico (e nisso ele se distingue do conhecimento empírico ou vulgar), quando o âmbito de extensão de um substantivo é limitado pelo acréscimo de um qualificativo (compreensão), pressupõe-se, sempre, que o substantivo designa o gênero, do qual o qualificativo designa a diferença específica. É óbvio que dos panfletários da ciência política do liberalismo francês do século referido não se poderiam licitamente exigir nem rigor lógico-formal nem conhecimento específico da doutrina jurídica. 
O equívoco lógico intrínseco daquela locução decorre de dois axiomas jurídicos: $a$. todos e quaisquer direitos só podem ser humanos, uma vez que o mundo do jurídico é o cultural; $b$. só pode ser sujeito (ativo ou passivo) de direito subjetivo o homem (os demais animais, os vegetais, os minerais e outros seres somente poderão ser objeto de tutela jurídica, nunca sujeitos).

Como, então, designar-se aquela categoria especial de direitos subjetivos (defendidos por remédios jurisdicionais em regra sumários, como os "writs"), de modo a distingui-los dos de outra categoria (defendidos pelas ações ordinárias)?

Houve quem, na Faculdade de Direito de São Paulo, já os tivesse designado "direitos subjetivos públicos" (Ráo, $O$ direito e a vida dos direitos, $\mathrm{p}$. 460 e ss.). Tal designação, cientificamente irreprochável, vinha de molde, mas para uma época em que a disciplina do tema era objeto de indagações de direito público interno (concebidos tais direitos como os oponíveis pelos indivíduos contra o Estado). Ademais, não se colocara, até então, a visão metodológica social do tema.

1.2. Metodologia adequada para a rigorosa catalogação e conceituação da matéria.

Impõe-se partir de determinados princípios da teoria geral do Direito, se se quiser chegar próximo não só de uma perfeita expressão terminológica como também de uma conceituação adequada à idéia que se examina. Tais princípios indicam-nos que a cada direito subjetivo corresponde um título aquisitivo; através de tais títulos (compra e venda, mútuo, concurso, ato do poder público, por exemplo) adquirem-se, no curso da vida, os direitos de proprietário de determinado prédio ou móvel, de credor de determinada importância, de acesso ou investidura em determinado cargo público, etc. São os direitos adquiridos.

Há, todavia, uma categoria de direitos de que o sujeito é titular não por aquisição no curso da vida; o título aquisitivo destes direitos especiais é o só nascimento, com personalidade. Se um ser nasce pessoa, torna-se ipso facto titular desses direitos. Ora, se tal ocorre, a locução que mais se adequaria para a designação dessa categoria especial de direitos subjetivos seria "direitos 
fundamentais da pessoa" ou "direitos essenciais à personalidade", para distinguilos dos da espécie dos "adquiridos".

Então ter-se-á, como corolário, a conceituação dessa categoria de direitos: aqueles ínsitos à personalidade.

O trabalho científico seguinte deverá ser, necessariamente, a identificação e individuação desses direitos. Para tal tarefa, deve o jurista valer-se de conhecimentos ancilares que lhe possa fornecer a Psicologia (ciência que se ocupa da personalidade). Foi essa a metodologia por que optou outro professor da Faculdade de Direito de São Paulo (Sampaio Dória, Direito constitucional, p. 689-764), para chegar a conclusões preciosas que em seguida sumariamos.

1.3. Identificação e individuação dos direitos fundamentais da pessoa.

Ora, a Psicologia indica-nos que a personalidade é fenômeno complexo, pluridimensional: é síntese integrativa de vários índices ou caracteres, cada um deles, por seu turno, objeto de uma ciência específica. Mas a mera Psicologia não explica a pessoa (Reale, Introdução à filosofia, p. 160).

$O$ índice mais aparente e elementar da personalidade é de ordem biológica: as manifestações anátomo-fisiológicas desse índice (vida, integridade física, autolocomoção) são tuteladas como direito fundamental. Outro é de ordem psicológica: o livre pensamento e sua manifestação. Existe também o de ordem sociológica: a vocação para a reunião e associação. Outro elemento é de ordem econômica: o trabalho e acumulação de seus frutos. Há o índice de ordem metafísica: crença e a manifestação exterior dela (culto). Há um índice, finalmente, de natureza política: a vocação para o exercício do poder (mediante acesso direto ou participação indireta). E como tais índices são constantes na personalidade, corolário da síntese integrativa deles é a igualdade.

A idéia de pessoa nasce da autoconsciência da dignidade do ser humano, que é dever-ser (Ibid., p. 160). 
2. EVOLUÇÃO DA TEORIA DOS DIREITOS FUNDAMENTAIS, NO PLANO INTERNO.

2.1. Do individualismo ao neoliberalismo.

A concepção individualista dos direitos fundamentais, no plano econômico (capitalismo), levou a Europa do século XIX a presenciar situações politicamente conflitivas, sobretudo em decorrência dos abusos no exercício da propriedade, do amealhamento do capital e da livre contratação do trabalho. A "questão social", crise dialética em que se defrontavam a tese da liberdade individual e a antítese do coletivismo, suscitou o surgimento do neo-liberalismo, como tentativa teórico-prática de solução sintética do conflito.

De conseqüência, procede-se a uma revisão da teoria original dos direitos fundamentais, que passam a ser concebidos não mais como de titularidade exclusiva da pessoa física ou jurídica individualizadamente consideradas: alguns daqueles direitos são fundamentais do indivíduo; outros são de titularidade da coletividade ou de grupos sociais (representados pelo Estado, autorizado, assim, a intervir no plano privado). Os chamados direitos sociais não são senão o produto da restrição que se permitiu ao Estado fazer, através de intervenção no plano privado, no antigo âmbito dos direitos individuais: a desapropriação, a propriedade coletiva do subsolo, o imposto sobre a renda, a regulamentação heterônoma dos contratos de trabalho, a restrição da autolocomoção aos limites do território nacional tornaram-se, por isso, o que grande número de estudiosos aprecia chamar de direitos fundamentais "de segunda geração".

Surge, no plano do direito constitucional interno, novo modelo de disciplina da matéria: a Carta de Weimar (que, depois da tradicional declaração de direitos fundamentais do indivíduo, passa também a proclamar os direitos fundamentais sociais).

2.2. A dimensão internacional dos direitos fundamentais da pessoa exige novo âmbito para a disciplina jurídica do tema.

O breve escorço, acima ensaiado, da evolução da teoria dos direitos fundamentais está a demonstrar um evidente equívoco no tratamento jurídico 
tradicional do tema. E que, ontognoseologicamente, o Estado (e, portanto, as ordens jurídicas constitucionais internas), surgido como exigência política no marco entre o feudalismo e a Idade Moderna, insere-se no mundo da cultura, que é criação e expressão da experiência humana. Por outro lado, a idéia de que a pessoa seja mera categoria histórica deve ser corrigida com a verificação de que "a pessoa é o valor-fonte de todos os valores" (Reale, ob. cit., p. 159-162).

Assim, a sede adequada para o tratamento jurídico do tema não é o Direito interno, ainda que de nível constitucional, senão o Direito Internacional, em que pontifica como ator e destinatário último das regras jurídicas a pessoa, como já alertava o gênio criativo do fundador Francisco de Vitória.

\section{EVOLUÇÃO DA TEORIA DOS DIREITOS FUNDAMENTAIS, NO PLANO INTERNACIONAL.}

\subsection{O indivíduo como sujeito de Direito Internacional Público.}

Ao final da Segunda Grande Guerra, criaram-se os Tribunais de Nuremberg e de Tóquio, com os atos constitutivos, respectivamente, de 8 de outubro de 1945 e de 19 de janeiro de 1946. Tipificaram-se, então, pela primeira vez em nível internacional, delitos imputáveis a pessoas físicas, indivíduos (sabendo-se que só a pessoa física pode ser agente de delito). A afirmação da responsabilidade criminal do indivíduo por crimes internacionais foi passo importantíssimo na evolução da teoria (Lafer, $A$ reconstrução dos direitos humanos: um diálogo com o pensamento de Hannah Arendt, p. 162-172), pouco importando os aspectos não-políticos e estritamente técnicos respeitantes aos princípios da anterioridade da lei penal e do juiz natural. Paradoxalmente, foram violados direitos fundamentais dos condenados, mas para um resultado altamente positivo que foi a afirmação teórica de que o indivíduo é responsável criminalmente no plano internacional.

Quanto à afirmação da titularidade ativa de direitos subjetivos, no plano internacional, o primeiro instrumento que formalmente a proclama é a Declaração Universal, aprovada pela Assembléia Geral das Nações Unidas a 10 de dezembro de 1948. Alguns entendem que as disposições da Declaração não são geradoras de obrigações jurídicas por parte dos Estados, porque tal 
documento não constitui um tratado (Rezek, Direito internacional público, p. 222). Outros sempre afirmaram o poder vinculante dessas resoluções (Marotta Rangel, $A$ Declaração Universal dos Direitos do Homem em seu vigésimo aniversário).

Com o advento do Pacto Internacional sobre Direitos Civis e Políticos, adotado pela Assembléia Geral das Nações Unidas a 16 de dezembro de 1966 e em vigor desde 1976, internacionalizou-se definitivamente a normatização do tema.

Fora do âmbito dos direitos fundamentais da pessoa, a Corte de Justiça das Comunidades Européias, criada pelo Tratado de Roma de 1957, confere capacidade processual às pessoas físicas e jurídicas de direito privado para intentar ações. $\mathrm{O}$ mesmo modelo inspirou a criação do Tribunal Andino de Justiça (Tratado de Cartagena de 1979).

\subsection{Instrumentos regionais.}

Na Europa, entrou em vigor em 1950 a Convenção sobre os Direitos Fundamentais. Esse instrumento, que contém dispositivos substanciais e instrumentais, criou uma Comissão regional, à qual têm acesso as pessoas físicas e jurídicas. A Comissão tem legitimidade processual para, como substituta, deduzir aquelas pretensões individuais perante a Corte de Justiça, sediada em Estrasburgo.

Inspirados nesse modelo, doze Estados do continente americano firmaram, em 22 de novembro de 1969, em São José da Costa Rica, a Convenção Americana sobre Direitos Fundamentais da Pessoa. O Brasil vem de ratificá-la, tendo ela já entrado em vigor em 18 de julho de 1978. Trata-se de Convenção aberta à adesão de todos os membros da OEA, sem limite no tempo. Tal instrumento é constituído de disposições substanciais e processuais, tendo previsto a criação de uma Corte Interamericana de Direitos Fundamentais, que já foi estruturada e está sediada em São José da Costa Rica. A Corte, tal como no modelo europeu ocorre, não conhece diretamente de pretensões individuais, senão quando deduzidas pela Comissão Interamericana de Direitos Fundamentais (organismo que já vinha anunciado no art. 112 da Carta da OEA, tal como reformulado em 1967 em Buenos Aires). 
No continente africano, celebrou-se também tratado sobre a obrigação jurídica, imposta aos Estados da OUA, de respeito aos direitos fundamentais da pessoa, mas ali há restrições quanto à garantia da efetividade de seus preceitos: indivíduos podem peticionar perante a Comissão, mas esta não lhes dará curso se não se caracterizarem violações graves ou massivas.

\subsection{Os direitos fundamentais chamados "de terceira geração".}

Os direitos fundamentais chamados "de segunda geração" (cf. 2.2 supra) foram enunciados já em instrumentos internacionais importantes, como o Pacto Internacional sobre Direitos Econômicos, Sociais e Culturais, adotado pela Assembléia Geral das Nações Unidas a 16 de dezembro de 1966, que entrou em vigor em 3 de janeiro de 1976.

Todavia, mais recentemente, fala-se em direito à paz, direito à segurança, direito ao meio ambiente, como direitos fundamentais "de terceira geração", não sem que se oponham críticas de ordem técnico-científica a essa concepção (Rezek, ob. cit., p. 223-224).

Resolução da Assembléia Geral das Nações Unidas (n. 41-128), de 4 de dezembro de 1986, contém importantíssima declaração quanto ao direito ao desenvolvimento como direito fundamental da pessoa. Os titulares do direito ao desenvolvimento são não só os Estados senão também os indivíduos (Bermejo Garcia e Dougan Beaca, El derecho al desarrollo: un derecho complejo con contenido variable, p. 211 e ss.). Foi demonstrado, por outro lado, a partir de experiência haurida em análise de casos apreciados pela Comissão de Direitos Humanos das Nações Unidas, que existe profunda e inequívoca relação entre o subdesenvolvimento do Estado e de seus cidadãos, de um lado, e as violações dos direitos fundamentais da pessoa, de outro lado (Pastor Ridruejo, La protección internacional de los derechos humanos y la cooperación para el desarrollo), de modo tal que a efetividade do direito ao desenvolvimento passa a ser direitocondição para o respeito aos direitos fundamentais da pessoa globalmente considerados. 


\section{ESTÁGIO ATUAL E PERSPECTIVAS.}

No estágio atual do desenvolvimento do chamado "Direito Internacional dos Direitos Humanos" (Garcia Amador, Dimensiones actuales de derecho internacional publico, p. 71-97), vários institutos consolidaram-se, a demonstrar a inexorável ințernacionalização do tema a partir de fins da Segunda Guerra. Alguns autores, como Hildebrando Accioly (Tratado de direito internacional público, p. 102 e 103), ensaiaram um rol de exemplos, nem sempre felizes, dos quais extrairemos os mais pertinentes, acrescentando-lhes outros:

a. Na "jurisdição de presas", o proprietário do navio e da carga tem capacidade processual, distinta da do Estado reclamante;

b. Nos casos de pirataria, a responsabilidade é do indivíduo e não do Estado de que é súdito;

c. A liberdade dos mares beneficia também, diretamente, o indivíduo;

d. A possibilidade de arbitragem internacional em que sejam partes um Estado e indivíduo súdito de outro Estado.

Estudiosos acrescentam, mais recentemente (Gilda Russomano, Direito internacional público, p. 186-187), a pertinente observação de que surgiram tribunais, no plano da jurisdição supraestatal, que não só admitem legitimidade ativa à pessoa privada, como existem, precisamente, para tutelar-lhe os direitos subjetivos: assim concebem-se os tribunais administrativos de várias organizações internacionais, como a própria ONU, a OEA, o BIRD e outras.

Quanto à proteção diplomática, duas são as faces do instituto. A primeira delas diz respeito ao dever de assistência, que incumbe ao Estado, aos súditos que no exterior estejam sendo sujeitos a medidas coercitivas lícitas pelas autoridades territoriais. Quanto à segunda face do instituto, respeitante aos atos ilícitos de que eles possam ser vítimas no exterior, o endosso parece-nos exemplo claro da tutela internacional de direitos fundamentais, porque, neste caso, o interesse deduzido em juízo pelo Estado que fala em nome próprio tem como titular o indivíduo; trata-se de fenômeno de substituição processual. Por isso ousamos discordar de eminentes escritores (Garcia Amador, ob. cit., p. 164 in fine) que, fundados em argumentação expendida em conhecido acórdão da Corte 
Internacional de Justiça, entendem que, no endosso, o Estado deduz em juízo pretensão de direito material própria.

Dois outros institutos merecem ser referidos: o asilo e o direito a uma nacionalidade (bem como o direito à naturalização, seu consectário).

\section{BIBLIOGRAFIA}

ACCIOLY, Hildebrando. Tratado de direito internacional público. $2^{\mathrm{a}}$ ed. Rio de Janeiro, 1956. v. 2.

BERMEJO GARCIA, R.; DOUGAN BEACA, J.D. El derecho al desarrollo: un derecho complejo con contenido variable. Anuario de Derecho Intermacional, Universidade de Navarra, n. 8, 1985.

BONAVIDES, Paulo. A nova universalidade dos direitos fundamentais. Revista Nomos, Fortaleza, vs. 9-10, ns. 1-2, jan-dez. 1990-91.

BOSON, Gerson de Brito Mello. Internacionalização dos direitos do homem. São Paulo : Sugestões Literárias, 1972.

DÓRIA, A. de Sampaio. Direito constitucional. $4^{\text {a }}$ ed. São Paulo : Max Limonad, 1958. v.1, t.2.

GARCIA AMADOR, F.V. Dimensiones actuales del Derecho Internacional Publico. Comunicação ao XVII Congresso do Instituto Hispano Luso Americano de Direito Internacional. San Lorenzo de el Escorial : IHLADI, 1992.

LAFER, Celso. A reconstrução dos direitos humanos: um diálogo com o pensamento de Hannah Arendt. $1^{\text {a }}$ reimpressão. São Paulo : Cia. das Letras, 1991.

LEWANDOWSKI, Enrique Ricardo. Proteção dos direitos humanos na ordem interna e internacional. Rio de Janeiro : Forense, 1984.

PASTOR RIDRUEJO, J.A. La protección internacional de los derechos humanos y la cooperación para el desarrollo. Comunicação ao XVII Congresso do Instituto Hispano-Luso-Americano de Direito Internacional. Madri : IHLADI, 1992.

RANGEL, Vicente Marotta. A Declaração Universal dos Direitos do Homem em seu vigésimo aniversário. Problemas Brasileiros, São Paulo, n. 70, 1969. 
RÁO, Vicente. O direito e a vida dos direitos. São Paulo : Max Limonad, 1958. v.2.

REALE, Miguel. Introdução à filosofia. São Paulo : Saraiva, 1988.

REZEK, José Francisco. Direito internacional público. São Paulo : Saraiva, 1989.

RUSSOMANO, Gilda Maciel Corrêa Meyer. Direito internacional público. Rio de Janeiro : Forense, 1989. v.1. 